\title{
COMPETÊNCIAS DO PROFISSIONAL DE ENFERMAGEM NA ATUAÇÃO EM ENFERMAGEM INTEGRATIVA
}

\author{
Nelson Augusto MENDES ${ }^{1}$, Luís Antônio RAMOS ${ }^{2}$, Ana Sarah Arana GONÇALVES ${ }^{3}$
}

\section{RESUMO}

A Enfermagem de Transporte Aeromédico é uma especialidade reconhecida pelo Conselho Federal de Enfermagem (COFEN), relacionada direta ou indiretamente às atividades desempenhadas no ambiente aéreo, sendo uma área que avança em conhecimento e extensão e que, atualmente, se faz tão necessária. A enfermagem é considerada uma profissão com centro nas interações, onde cada indivíduo, pela vivência de um projeto de saúde, acaba se tornando singular, único e indivisível em um momento único de cuidado, assim, os profissionais tornam-se atores do processo de alteração e os contextos são imperativos ao desenvolvimento de competências. Desta forma, o presente trabalho tem como objetivo identificar as principais competências que um enfermeiro aeromédico precisa ter para prestar cuidados gerais em serviço aeromédico e aeroespacial, a partir do levantamento bibliográfico utilizando as principais base de dados. O desenvolvimento de suas competências é considerado um processo com complexidade e interativo que tem ocorrência perante o enfermeiro e o universo que o circunda. Como ator desse processo de evolução, tem importância o conhecimento de que maneira o enfermeiro acaba compreendendo e concretizando as competências com referência como veículo para aplicação eficaz de seus conhecimentos e habilidades. Assim, é possível chegar à conclusão que, a competência é resultante de um saber agir, de um querer agir e de um poder agir onde a qualidade do atendimento, com equipe treinada e aclimatada e cientes da segurança e técnicas propostas pelo Serviço aeromédico, selam as possibilidades de êxito em uma operação que com frequência oferece riscos e podem ser minimizados.

Palavras-chave: Enfermagem Integrativa, Cuidado, Enfermeiro Aeromédico.

\section{INTRODUÇÃO}

A enfermagem é considerada uma profissão com centro nas interações, onde cada indivíduo, pela vivência de um projeto de saúde, acaba se tornando singular, único e indivisível em um momento único de cuidado. O avanço da tecnologia vem determinando diversas centralidades nas técnicas, enquanto que o desenvolvimento e alterações nos locais trabalhistas, com relação a inovação da tecnologia e as modificações na organização do trabalho, fazem ter imersão novas lógicas empresariais, onde é procurado a valorização do fator humano nas instituições. O fato humano, torna a função demandante de sensibilidade constante, e devido à complexidade dos atendimentos, o contínuo aperfeiçoamento técnico faz-se necessário, sobretudo em atuações durante o transporte aeromédico.

\footnotetext{
${ }^{1}$ Pós-Graduado Enfermagem Aeroespacial - nelson@censupeg.com.br

2 Pós-Graduado Enfermagem Aeroespacial - ramosluis.antonio1965@gmail.com

${ }^{3}$ Pós-Graduanda em Engenharia Biomédica - ana s.a.g@hotmail.com
} 
O transporte aeromédico pode ser descrito como um deslocamento de pacientes em estados críticos, cujos quais, em grande parte das vezes, constituem a única opção viável para que o atendimento especializado seja propiciado ao indivíduo (SCUIDDIATO et al., 2012), exigindo do enfermeiro de bordo, capacitação para suprir as demandas necessárias durante o transporte. No Brasil, os fatores que contribuem diretamente para a necessidade desses serviços, estão relacionados aos aspectos de expansão territorial e distribuição heterogênea da população e regiões de difícil acesso (GENTIL, 1997).

$\mathrm{Na}$ prática, diversas pesquisas da área de enfermagem fazem efetivação do relacionamento perante competência e o exercício profissional, a qual os profissionais tornam-se atores do processo de alteração e os contextos são imperativos ao desenvolvimento de competências. Desta forma, o presente trabalho tem como objetivo identificar as principais competências que um enfermeiro aeromédico precisa ter para prestar cuidados gerais em serviço aeromédico e aeroespacial.

\section{METODOLOGIA}

Esta revisão sistemática utilizou bases eletrônicas como Google Scholar, ScienceDirect, e PubMed para consultas sobre o tema. O levantamento bibliográfico acerca da atuação dos enfermeiros foi realizado utilizando os descritores: remoção aérea, transporte aeromédico, cuidados em enfermagem, enfermagem integrativa. Para tanto, os estudos foram escolhidos pelo título, posteriormente pelo resumo e, por último pelo texto completo. Os artigos selecionados foram publicados nas últimas duas décadas, sendo escritos e publicados em português ou inglês.

\section{RESULTADOS E DISCUSSÕES}

As competências relacionadas ao enfermeiro nos cuidados foram de forma inicial com descrição no referencial de competência do enfermeiro de cuidados gerais, documentação que teve publicação no ano de 2003, onde tem apresentação 96 competências, que possuem relação com um nível de desempenho profissional demonstrador de uma aplicação eficaz do conhecimento e das capacidades, fazendo a inclusão do ajuizar (GUEDES et al. 2016). Nessa documentação, as competências possuem agrupamento em 3 domínios, que são: prática profissional, ética e legal, prestação e gestão dos cuidados e desenvolvimento profissional. 
Não menos importante é apresentando o Código Deontológico dos enfermeiros, com inserção no Estatuto da Ordem dos Enfermeiros através da Lei no 11/2009, que faz a criação de uma base deontológica para praticar a profissão, a qual a disposição em seu primeiro artigo diz sobre a competência e aperfeiçoamento profissional. Seu artigo 88 pontua que, na excelência do exercício, o enfermeiro precisa buscar em todo excelência no exercício, assumindo o dever de fazer análise de forma regular o trabalho em efetuação e reconhecimento das eventuais falhas. (GUEDES et al. 2016). Assim, a competência e aperfeiçoamento profissional tornam-se valores universais a terem observação no relacionamento profissional (RUTHES E CUNHA, 2009).

Ademais, a Lei do Exercício Profissional da Enfermagem nำ 7.798 de 25 de junho de 1986, também dispõe sobre o exercício do enfermeiro sob o contexto de sua autonomia no que tange a organização, atuação e coordenação da assistência aos pacientes críticos que necessitam de maior nível de complexidade pactuando com a Resolução Cofen 375/2011 que dispõe sobre a presença do Enfermeiro no Atendimento Pré-Hospitalar e InterHospitalar, em situações de risco conhecido ou desconhecido (SCUIDDIATO et al., 2012; BRASIL, 1986; COFEN, 2011). Scuiddiato et al., (2012), também reforçam que na Portaria GM n. 2.048 de 05 de novembro de 2002 há o anteparo legal para o exercício desta atividade, a qual determina a necessidade de especialização dos profissionais que constituem as equipes de transporte aeromédico.

Pode-se vincular a origem do transporte aeromédico, desde os períodos de guerras em que o transporte de feridos precisava ser rápido. A importância da questão da especialização na área é tratada aqui, pois apesar de relativamente pouco abordada em instituições de ensino e de se tratar de uma área de atuação diferenciada, consta na Resolução do Conselho Federal de Enfermagem n. 389/2011 a especificação também no atendimento também a área aeroespacial (COFEN, 2011).

O papel do enfermeiro de bordo é imprescindível levando em consideração que a equipe trabalha na multidisciplinariedade em prol da qualidade de vida do paciente e assim, consegue exercer suas atribuições de forma funcional e otimizada (BRASIL, 2010). Existem alguns critérios gerais para que se admita um tripulante em uma equipe de transporte aeromédico, requisitos esses que devem ser criteriosamente respeitados já que em se tratando de transporte aéreo, alterações como altitude, tempo de voo e capacidade física do profissional são importantes (BRASIL, 2010). 
Portanto, o enfermeiro que atua no serviço aeromédico deve ter noções de aeronáutica, de fisiologia de voo, conforme o priorizado nas recomendações da Diretoria de Saúde Aeronáutica e da Divisão de Medicina Aeroespacial. O conhecimento necessário ao enfermeiro de bordo, de maneira geral, deve incluir noções de procedimentos realizados sob contextos normais e os de emergência em voo; evacuação de emergência; segurança no interior e ao redor da aeronave; fisiologia respiratória; disbarismos; ritmo circadiano; gases, líquidos e vapores tóxicos em aviação e cuidados específicos da saúde do paciente durante o transporte aéreo (IBACBRASIL, 2012; BRASIL, 2002; BRASIL, 2010).

Diante do exposto, podemos dizer que o enfermeiro deve ter noções intrínsecas do atendimento aeromédico, onde podemos destacar em consonância com o esclarecido na Portaria GM no 2.048/2002, o conhecimento acerca da fisiologia de voo para que melhor possa atender as necessidades do paciente sem que, no entanto, se torne susceptível a qualquer risco ocupacional previsível. Por fim, o conhecimento relacionado com a percepção dos enfermeiros de cuidados gerais acerca do referencial de competências, ao nível compreensivo e concretização destas, assim como a maneira de como essas possuem operacionalização na prática, tem revelação importante para desenvolver estratégias organizativas ao nível das instituições trabalhistas, detecção das necessidades de formação e melhora de avaliar o desempenho, visando a melhora os cuidados de enfermagem (GUEDES et al. 2016).

\section{CONSIDERAÇÕES FINAIS}

Como foi possível ver, a competência dos enfermeiros é resultado das experiências com domínio, e reflete-se quando o trabalho tem automatização, dependendo menos do controle cognitivo e da reflexão no contexto da adaptação da conduta às alterações constantes do contexto da prática.

O desenvolvimento das competências é considerado um processo com complexidade e interativo que tem ocorrência perante o enfermeiro e o universo que o circunda. Como ator desse processo de evolução, tem importância o conhecimento de que maneira o enfermeiro acaba compreendendo e concretizando as competências com referência como veículo para aplicação eficaz de seus conhecimentos e habilidades. Assim, é possível chegar à conclusão que, a competência é resultante de um saber agir, de um querer agir e de um poder agir. 


\section{REFERÊNCIAS}

BRASIL. Ministério da Saúde. Lei no 7.498/86 de 25 de junho de 1986. Dispõe sobre a regulamentação do exercício da Enfermagem e dá outras providências. Brasília, 1986. Disponível em: <http://novo.portalcofen.gov.br/lei-n-749886-de-25-de-junho-de1986 4161.html >. Acesso em: 23 mar. 2020.

BRASIL. Ministério da Saúde. Portaria GM/MS n²048, de 05 de novembro de 2002. Aprovar, na forma de Anexo desta Portaria, o Regulamento Técnico dos Sistemas Estaduais de Urgência e Emergência. Disponível em: $<$ http://www.saude.mg.gov.br/atos normativos/legislacao-sanitaria/estabelecimentos-desaude/urgencia-e-emergencia/portaria 2048 B.pdf>. Acesso em: 23 mar. 2020.

BRASIL. Ministério da Saúde. Diretrizes e Protocolos de Atendimento Aeromédico. Brasília, $2010 . \quad$ Disponível em: <http://www.samu192df.com.br/samu/aeromedico/MostradiretrizesAero.jsp?idnoticia=10>. Acesso em: 22 mar. 2020

COFEN. Conselho Federal de Enfermagem. Resolução Cofen 290/2004 - Revogada pela Resolução Cofen no 389/2011. Fixa as Especialidades de Enfermagem. Brasília, 2011. Disponível em: <http://novo.portalcofen.gov.br/resoluo-cofen-2902004-revogada-pelaresoluo-cofen-n-3892011 4326.html>. Acesso em: 22. Mar. 2020.

COFEN. Conselho Federal do Paraná. Resolução Cofen 375/2011. Dispõe sobre a presença do Enfermeiro no Atendimento Pré-Hospitalar e Inter-Hospitalar, em situações de risco conhecido ou desconhecido. Disponível em: <http://novo.portalcofen.gov.br/resoluocofen-n-3752011 6500.html>. Acesso em: 23 mar. 2020.

DIAS, F. Construção e Validação de um Inventário de Competências: Contributos para a Definição de um Perfil de Competências do Enfermeiro com Grau de Licenciado. Loures, Lusociência, 2006.

FIGUEIRA, F. Valores universais na prática de Enfermagem: competência e aperfeiçoamento. Revista Ordem dos Enfermeiros, 15, Dezembro 2004.

GENTIL, R. C., Aspectos Históricos e Organizacionais da Remoção Aeromédica: A Dinâmica da Assistência de Enfermagem. Rev. Esc. Enfermagem USP, v. 31, n. 3, p. 452467. São Paulo, 1997. Disponível em: <http://www.scielo.br/pdf/reeusp/v31n3/v31n3a08.pdf>. Acesso em: 23 mar. 2020. 
GUEDES, V. M. S.; FIGUEIREDO, M. H. S.; APÓSTOLO, J. L. A. Competências do enfermeiro de cuidados gerais em cuidados de saúde primários: da compreensão à concretização. Rev. Enf. Ref. vol.serIV no.8 Coimbra mar. 2016

IBACBRASIL. Instituto Base de Conteúdos e Tecnologias Educacionais. Conheça a Enfermagem aeroespacial. Curitiba, 2012. Disponível em: $<$ http://www.ibacbrasil.com/noticias/enfermagem/conheca-a-enfermagem-aeroespacial>. Acesso em: 23 mar. 2020.

MENDONÇA, S. S.. Competências profissionais dos enfermeiros: A excelência do cuidar. Lisboa, Portugal: Editorial Novembro, 2009.

OLIVEIRA, P. C. M. Auto-eficácia específica nas competências do enfermeiro de cuidados gerais: percepção dos estudantes finalistas do curso de licenciatura em enfermagem. Tese de mestrado, Universidade Portucalense Infante D. Henrique do Porto, 2010.

PASSOS, I. P. B. D., et al. Transporte aéreo de pacientes: análise do conhecimento científico. Rev Bras Enferm., v. 64, n. 6, p. 1127-1131. Brasília, 2011. Disponível em: $<$ http://www.scielo.br/pdf/reben/v64n6/v64n6a21.pdf >. Acesso em: 22 mar. 2020.

PILOTO POLICIAL. Portal de Aviação de Segurança Pública e Defesa Civil. Histórico do Resgate Aeromédico. São Paulo, 2010. Disponível em: $<$ http://www.pilotopolicial.com.br/as-origens-do-resgate-aeromedico-e-como-surgiu-emsao-paulo/>. Acesso em: 22 mar. 2020

ROCHA, P. K., et al. Assistência de Enfermagem em Serviço Pré-Hospitalar e Remoção Aeromédica. Rev. Bras. Enfermagem., v. 56, n. 6, p. 695-698. Brasília, 2003. Disponível em: <http://www.scielo.br/pdf/reben/v56n6/a22v56n6.pdf >. Acesso em: 23 mar. 2020

RUTHES, R. M.; CUNHA, I. C. K. O. Competências do enfermeiro na gestão do conhecimento e capital intelectual. Rev Bras Enferm, Brasília 2009 nov-dez; nov-dez; 62(6): $901-5$

SCHWEITZER, G.; NASCIMENTO, E. R. P. do; MOREIRA, A. R.; BERTONCELLO, K. C. G. Protocolo de cuidados de enfermagem no ambiente aeroespacial a pacientes traumatizados: cuidados antes do voo. Rev. Bras. Enferm. v. 64, n.6, p. 1056-1066. Brasília, 2011. Disponível em: <http://www.scielo.br/pdf/reben/v64n6/v64n6a11.pdf>. Acesso em: 22 mar. 2020. 
SCUISSIATO, D. R.; BOFFI, L. V.; ROCHA, R. da R. da; MONTEZELI, J. H.; BORDIN, M. T.; PERES, A. M. Compreensão de enfermeiros de bordo sobre seu papel na equipe multiprofissional de transporte aeromédico. Rev. Bras. Enferm. v. 65, n.4 , p. 14-20. Brasilia, 2012.

em:

<http://www.scielo.br/pdf/reben/v65n4/a10v65n4.pdf>. Acesso em: 22 mar. 2020. 